\title{
STUDY ON POLLINATION AND SELECTION OF THE MOST SUITABLE POLLINIZERS FOR COMMERCIAL PEAR CULTIVARS (PYRUS COMMUNIS L.) IN IRAN
}

\author{
Maryam TATARI*1 ${ }^{*}$, Ayoubali GHASEMI ${ }^{1}$, Asghar MOUSAVI ${ }^{2}$, Hamidreza BAHRAMI ${ }^{1}$ \\ ${ }^{1}$ Horticulture Crops Research Department, Isfahan Agricultural and Natural Resources Research and Edu- \\ cation Center, Agricultural Research, Education and Extension Organization (AREEO), Isfahan, Iran \\ ${ }^{2}$ Horticulture Crops Research Department, Chahar-Mahal va Bakhtiari Agricultural and Natural Re- \\ sources Research and Education Center, Agricultural Research, Education and Extension Organization \\ (AREEO), Shahrekord, Iran
}

Received: August 2017; Accepted: November 2017

\begin{abstract}
The cultivated pear is an economically important fruit tree species of genus Pyrus in which often gametophytic self-incompatibility occurs. Therefore, this species need to be pollinated by cross-compatible cultivars that bloom in the same time. Selection of appropriate pollinizers for pear cultivars is very important to produce commercial yield. 'Sebri', 'Shahmiveh' and 'Natanzi' are the best commercial cultivars in Iran, but the lack of a suitable source of pollen can reduce productivity. In order to select the most suitable pollinizer for these pear cvs, an experiment was conducted in which they were considered as pollen recipients and 'Coscia', 'Bartlett' and 'Sardroud' along with 'Sebri', 'Shahmiveh' and 'Natanzi' were evaluated as pollen donors. This research was conducted as a factorial experiment in randomized complete block design for four years. Recipient and donor cultivars had almost overlapping flowering time. The flower buds on selected branches were emasculated at balloon stage and then were counted and isolated with cotton tissue bags. Pollen grains of these pollinizers were collected in the laboratory. Isolation bags were taken off from the branches and emasculated flowers were pollinated with pollen grains of listed pollinizers during receptibility of stigma. The number of pollinated flowers was counted, and branches were covered again with the bags. The results showed that for 'Sebri' the best pollinizer was 'Coscia' with 5.7\% fruit set, for 'Shahmiveh' 'Bartlett' cv. with 5.8\% of fruit set and for 'Natanzi', 'Shahmiveh' with $5.5 \%$ of fruit set.
\end{abstract}

Key words: 'Shahmiveh', 'Sebri', 'Natanzi', pollen recipient, pollen donor

\section{INTRODUCTION}

One of the causes of inadequate fertility of pear trees and low yield per unit area is the self-incompatibility in flowers of pear trees. Most pear cultivars are completely or partially self-incompatible and some of the pear cultivars are also cross-incompatible (Zeratgar et al. 2012). Self-incompatibility is the main factor; therefore, the location of pollinator trees in the orchard must be fixed beforehand (Ershadi et al. 2010).

Although some pear cultivars have the ability to produce fruit as a result of self-pollination or without pollination, but to obtain an economical yield with desirable quality, it is necessary to use suitable pollen cultivars considering the overlapping flowering time. It is proposed that if 5-8\% of the pear flowers on the tree are converted into fruit, the yield production will be accepted economically (Jalili Marandi 2002). Without suitable pollination, only a few seeds are produced in the fruit, which results in producing of small and bad shaped fruits (Mohammad Khani et al. 2002). Relative or semi-compatibility will also lead to yield reduction (Zisovich et al. 2004).

There are several methods to study the compatibility/incompatibility of different cultivars and 
determination of suitable pollinizer for them (Ortega \& Dicenta 2004). These methods include controlled pollination, observation of pollen tube growth under fluorescence, $S$-ribonuclease analysis from styles, $S$-allele-specific DNA amplification using polymerase chain reaction (PCR) and nucleotide sequencing of DNA fragments related to incompatibility (Ortega \& Dicenta 2004; Mousavi et al. 2014). The controlled pollination allows to estimate the performance of several cultivars in the orchard, so this method is recommended to determine the appropriate pollinizer sets (Mahmoudi et al. 2007). Study of controlled pollination is important because simultaneously, overlapping flowering time should be checked (Ramírez \& Davenport 2013; (Dorostkar et al. 2011).

Gharghani et al. (2009) reported that, at least for apple, the balloon stage is a proper stage of flower development for emasculation to prevent the production of progeny by self-pollination. Atefi (1990) carried out some experiments to determine pollinizers for 'Shahmiveh Karaj', 'Sardroud', 'Domkaj', 'Williams', 'Beurre Giffard', 'Beurre Hardy', 'Spadona' and 'Duchess' and proposed the best pollinizers for each cultivar. Mohammad Khani et al. (2002) reported that 'Shahmiveh' is completely self-incompatible and 'Coscia' as well as 'Bartlet' are the best pollinizers for this cultivar what results in higher yields than with other pollinizers. In another study, two recipient cultivars including 'Packham's Triumph' and 'Lemon Bergamot' were pollinated with 'Josephine', 'Nashi', 'Winter Nelis', 'Lemon Bergamot' and Pyrus betulifolia, Pyrus boissieriana and Pyrus lindleyi pollen. Some pollinators, such as 'Winter Nelis' and 'Josephine', increased the fruit set percentage of 'Packham's Triumph'. Cultivars 'Nashi', 'Lemon Bergamot', 'Josephine' and 'Winter Nelis' and more seeds in 'Packham's Triumph' (Sharifani 2002). Sadat Mousavi (2009) compared the self-incompatibility of Asian and European pears. He reported that there were three groups: self-compatible, semi-selfcompatible and self-incompatible, amongst the Asian pear cultivars, but all of the European pears including 'Spadona', 'Passe Crassane', 'Felestini', 'Beurre Bosc', 'Louise Bonne', 'Coscia', 'Shahmiveh', 'Shahak', 'Sardroudi' and a genotype of Khoj were completely self-incompatible. It should be noted that environmental factors, especially temperature, are effective in the fruit setting. Temperature affects the maturity of stigma and ovule, pollen germination, pollen tube growth and, finally, length of pollination period. The activity of honey bees is also influenced by the temperature (Khadivi 2012).

Some regions of Iran because of its favorable climatic conditions are appropriate for the cultivation of pear trees. The main cause of low yield of pear trees is the lack of suitable and compatible pollinizer for main cultivar. Most of the local cultivars are self-incompatible and they need to be pollinated by compatible pollen to produce economical yield. The aim of this study was to determine the best pollinizers for commonly grown cultivars 'Sebri', 'Shahmiveh' and 'Natanzi' based on fruit setting and on some quantitative traits of fruits.

\section{MATERIAL AND METHODS}

\section{Plant material and pollination}

A pear orchard planted in 2012 in Agricultural Research Center of Isfahan, Iran, consisted of uniform trees of the same age. 'Sebri', 'Shahmiveh' and 'Natanzi' pear cultivars were selected as pollen recipients and 'Coscia', 'Bartlett' as well as 'Sardroud', 'Sebri', 'Shahmiveh' and 'Natanzi' were selected as pollen donors (Table 1). This research was conducted as a factorial experiment in randomized complete block design with four replications during four years (2012-2015). In addition to the controlled pollination, two treatments including lack of pollination and open pollination were also carried out. For each replication, 50 flowers were emasculated and pollinated.

At first, the flowering time of recipient and donor of the studied cultivars was recorded. The opening of $10 \%, 80 \%$ and $95 \%$ of flowers were considered as the beginning of flowering, full bloom and the end of flowering stages, respectively (Gharghani et al. 2009).

Some traits of recipient parents have been shown in Table 2 . These cultivars are characterized by a unique quality of fruits and are sold at high prices. 
Table 1. Experimental scheme

\begin{tabular}{lcccccccc}
\hline \multirow{2}{*}{$\begin{array}{c}\text { Recipient } \\
\text { cultivars }\end{array}$} & \multicolumn{9}{c}{ Pollinizers (donor parents) } & Open & No \\
\cline { 2 - 8 } pobri' & 'Natanzi' & 'Shahmiveh' & 'Bartlett' & 'Sardroud' & 'Coscia' & pollination & pollination \\
\hline 'Shahmiveh' & + & + & + & + & + & + & + & + \\
'Sebri' & + & + & + & + & + & + & + & + \\
'Natanzi' & + & + & + & + & + & + & + & + \\
\hline
\end{tabular}

Table 2. Characteristics of recipient cultivars 'Sebri', 'Shahmiveh' and 'Natanzi'

\begin{tabular}{ll}
\hline \multicolumn{1}{c}{ Cultivar/ genotype } & \multicolumn{1}{c}{ Characteristics } \\
\hline 'Sebri' & $\begin{array}{l}\text { Unique cultivar, medium tree growth vigor, very early-flowering, very late fruiting, } \\
\text { fruits with large size, uniform, juicy, firm tissue, fragrant with very good quality prop- } \\
\text { erties and very long storage period }\end{array}$ \\
\hline 'Shahmiveh' & $\begin{array}{l}\text { Medium tree growth vigor with widespread growth habit, intermediate flowering and } \\
\text { mid-season fruiting, fruit with large size and uniformity, juicy, fragrant with high astrin- } \\
\text { gency and desirable quantitative and qualitative characteristics }\end{array}$ \\
\hline 'Natanzi' & $\begin{array}{l}\text { Medium tree growth vigor with widespread growth habit, late flowering and extremely } \\
\text { late fruiting, large fruit and juicy with great aroma }\end{array}$ \\
\hline
\end{tabular}

\section{Preparation and collection of pollen grains}

Branches containing flower buds of donor parents were cut in the second half of March and they were placed in the pots containing $4 \%$ sucrose solution at room temperature $\left(22-25^{\circ} \mathrm{C}\right)$. After the opening of flowers, their anthers were removed and placed in petri dishes to dry and release pollen grains. The released pollen grains of each cultivar were separately stored in small glass containers in refrigerator at $4{ }^{\circ} \mathrm{C}$ until the crosses was performed.

\section{Pollen test for germination ability}

To check germination ability pollen was cultured on a medium containing $15 \%$ sucrose, $20 \mathrm{ppm}$ boric acid and $1 \%$ agar and incubated at $25^{\circ} \mathrm{C}$ (Hormaza \& Herrero 1996). After $24 \mathrm{~h}$, the germinated pollen grains were counted using binocular $(\times 10)$. Pollen grains with higher than $75 \%$ of germination were used for crosses (Zeratgar et al. 2012).

\section{Emasculation and controlled pollination}

Four trees of each recipient parent were selected as replications. In each of them, eight branches that were almost uniform in the vegetative growth and in number of flower buds were selected. The flowers were emasculated at the balloon stage with forceps and scalpel and weak and immature flower buds and opened flowers were removed at the same time. The whole branch with emasculated flowers were covered with cloth bags. Hands and appliances were disinfected with $70 \%$ ethanol, and pollination was carried out with small brushes. For this purpose, each branch was removed from the bag and their flowers were individually pollinated with selected pollinizers at the time of stigma receptibility. The pollinated flowers were counted and covered with the bags. The pollination was repeated on the next day. For determination of self-compatibility in pear cultivars, isolated flowers of one branch were manually pollinated with pollen of the same cultivar. In order to determine the parthenocarpy in each recipient cultivar, the flowers of one of the branches were emasculated at the balloon stage without any further pollination. On each tree, a branch with counted flowers was considered as open pollination (control) treatment.

\section{Determination of fruit set}

The number of fruits in each treatment was counted and calculated per 100 flowers for 3, 7 and 17 weeks after pollination. Regarding the occurrence of abortion and natural thinning until the June drop, the number of fruits in the third recording time was considered as the final fruit set (Sanzol \& Herroro 2002).

\section{Statistical analysis of data}

Data were analysed as a factorial experiment in a randomized complete block design with four replications using SAS software. Means were compared using protected LSD test. The data on the fruit set percentage were normalized with ArcSin formula and then analysed statistically. 


\section{RESULTS}

\section{Overlapping of flowering time}

The flowering period of the studied cultivars is presented in Table 3. 'Coscia' and 'Sebri' were early flowering with the shortest flowering periods, whereas 'Sardroud' and 'Natanzi' were late flowering with the longest flowering periods.

\section{Pollen germination}

The pollen grains germination of the evaluated cultivars was between $78 \%$ and $88 \%$, which showed that most of the pollen grains was capable of fertilization (Table 4).

\section{Fruit set and seed numbers per fruit}

The interaction of the recipient and donor parents on the number of fruits, seeds and fruit set percentages were significant at $1 \%$ probability level (Table 5). Similarly, pollinizer parents have a significant effect on all three evaluated traits, whilst the pollen recipient parents were effective only on the number of fruits. The interaction of year and donor parent had a significant difference in the number of fruits at $5 \%$ probability level. Generally, the effect of year on measured traits was not significant, indicating the relative stability of cultivars in fruiting.

Table 3. The flowering period of pear cultivars (four years average)

\begin{tabular}{|c|c|c|c|c|c|c|c|c|c|c|c|c|c|c|c|c|c|c|c|c|c|c|c|c|c|c|}
\hline \multicolumn{27}{|c|}{ March- April } \\
\hline & 25 & 26 & 27 & 28 & 29 & 30 & 31 & 1 & 2 & 3 & 4 & 5 & 6 & 7 & 8 & 9 & 10 & 11 & 12 & 13 & 14 & 15 & 16 & 17 & 18 & 19 \\
\hline 'Coscia' & & & & & & & & & & & & & & & & & & & & & & & & & & \\
\hline 'Sardroud' & & & & & & & & & & & & & & & & & & & & & & & & & & \\
\hline 'Bartlett' & & & & & & & & & & & & & & & & & & & & & & & & & & \\
\hline 'Shahmiveh' & & & & & & & & & & & & & & & & & & & & & & & & & & \\
\hline 'Sebri' & & & & & & & & & & & & & & & & & & & & & & & & & & \\
\hline 'Natanzi' & & & & & & & & & & & & & & & & & & & & & & & & & & \\
\hline
\end{tabular}

Table 4. Germination percentage of pollen grain in various pear cultivars $\pm \mathrm{SD}$

\begin{tabular}{ccccccc}
\hline Cultivar & 'Bartlett' & 'Shahmiveh' & 'Natanzi' & 'Coscia' & 'Sebri' & 'Sardroud' \\
\hline Germination percentage & $88 \pm 7.2$ & $85 \pm 6.97$ & $84 \pm 9.89$ & $84 \pm 7.1$ & $80 \pm 4.4$ & $78 \pm 7.64$ \\
\hline
\end{tabular}

Table 5. Analysis of variance for effect of pollen donor and recipient cultivars on measured characteristics

\begin{tabular}{lcccc}
\hline Source of variation & $\begin{array}{c}\text { Degrees } \\
\text { of freedom }\end{array}$ & \multicolumn{3}{c}{ Mean square } \\
\cline { 3 - 5 } & 3 & Fruit number & Seed number & Fruit set $(\%)$ \\
\hline Year & 12 & $0.47^{\mathrm{ns}}$ & $0.29^{\mathrm{ns}}$ & $0.0026^{\mathrm{ns}}$ \\
Year $\times$ replication & 2 & $0.14^{\mathrm{ns}}$ & $0.15^{\mathrm{ns}}$ & $0.0001^{\mathrm{ns}}$ \\
Recipient parent & 7 & $0.57^{* *}$ & $0.46^{\mathrm{ns}}$ & $0.0003^{\text {ns }}$ \\
Donor parent & 14 & $0.96^{* *}$ & $8.14^{* *}$ & $0.0042^{* *}$ \\
Recipient $\times$ donor & 6 & $0.42^{* *}$ & $1.21^{* *}$ & $0.0028^{* *}$ \\
Year $\times$ recipient & 21 & $0.02^{\text {ns }}$ & $0.14^{\text {ns }}$ & $0.0007^{\text {ns }}$ \\
Year $\times$ donor & 42 & $0.11^{*}$ & $0.06^{\text {ns }}$ & $0.0001^{\text {ns }}$ \\
Year $\times$ recipient $\times$ donor & 276 & $0.05^{\text {ns }}$ & $0.07^{\text {ns }}$ & $0.0001^{\text {ns }}$ \\
Error & 383 & 0.14 & 0.105 & 0.011 \\
Total & - & - & - & - \\
CV\% & 18.46 & 19.53 & 17.29 \\
\hline
\end{tabular}

${ }^{* * *}$, and ${ }^{\mathrm{ns}}$ : Significant at the $1 \%$ and $5 \%$ probability level and non-significant, respectively 
'Bartlett' (5.83\%) and then 'Coscia' (5.24\%) as pollinizers produced the highest fruit set percentage in 'Shahmiveh' (Table 6). The highest fruit number (6.5), seed number (4.37) and fruit set percentage $(5.7 \%)$ in 'Sebri' were obtained by pollination with 'Coscia'.

The largest number of fruits (6.0), seeds (4.25) and the highest percentage of fruit set $(5.48 \%)$ in 'Natanzi' were obtained in result of pollination with 'Shahmiveh'. Also, 'Sardroud' cultivar with 5.06\% of fruit set was a suitable pollinizer for 'Natanzi'. Fruit number and fruit set percentage in self-pollination of 'Natanzi', 'Sebri' and 'Shahmiveh' cultivars were lesser than those in no pollination treatment.

According to the results in Table 7, the highest fruit number resulting from open pollination was in the first year of experiment (6.41). In the second and third years, open pollination and 'Sardroud' pollinizer did not significantly differ with each other and had the highest number of fruits. 'Coscia' pollinizer had the highest average of fruit number (5.33) in the fourth year. In the fourth year, the fruit number obtained in result of open pollination decreased and superiority of open pollination was reduced.

A fruit number obtained as a result of lack of pollination varied in years.

Study of meteorological data related to average, minimum and maximum daily temperatures during March, April and May within four years showed that the significant effect of the year in this experiment was not related to changes in temperature (data not shown).

Table 6. Mean of fruit set percentage, seed and fruit number of different pollination compounds, open pollinated and not pollinated treatments $\pm \mathrm{SD} ; \mathrm{n}=50$

\begin{tabular}{|c|c|c|c|c|}
\hline $\begin{array}{c}\text { Recipient } \\
\text { parent }\end{array}$ & Donor parent & Fruit number & Seed number & Fruit set (\%) \\
\hline Natanzi & Bartlett & $3.68 \pm 1.25 \mathrm{i}$ & $2.06 \pm 1.23 \mathrm{gh}$ & $3.46 \pm 0.99 \mathrm{j}$ \\
\hline Natanzi & No pollination & $2.43 \pm 1.51$ & $0 \pm 01$ & $2.33 \pm 1.42 \mathrm{n}$ \\
\hline Natanzi & Open pollination & $5.37 \pm 0.95 f$ & $2.93 \pm 0.92 \mathrm{de}$ & $4.33 \pm 0.68 \mathrm{gh}$ \\
\hline Natanzi & Coscia & $3.37 \pm 1.14 \mathrm{j}$ & $2.56 \pm 1.03 f$ & $3.24 \pm 1.07 \mathrm{k}$ \\
\hline Natanzi & Natanzi & $2.06 \pm 1.48 \mathrm{mn}$ & $1.25 \pm 0.93 \mathrm{k}$ & $2 \pm 1.42 \mathrm{o}$ \\
\hline Natanzi & Sardroud & $5.75 \pm 1.18 \mathrm{de}$ & $4 \pm 0.96 b$ & $5.06 \pm 0.83 \mathrm{e}$ \\
\hline Natanzi & Sebri & $2.31 \pm 1.491 \mathrm{~m}$ & $1.62 \pm 1.02 \mathrm{ij}$ & $2.74 \pm 2.15 \mathrm{~m}$ \\
\hline Natanzi & Shahmiveh & $6 \pm 1.15 \mathrm{~cd}$ & $4.25 \pm 0.77 \mathrm{ab}$ & $5.48 \pm 0.95 c$ \\
\hline Sebri & Bartlett & $3.06 \pm 1.43 \mathrm{k}$ & $2.68 \pm 1.44 \mathrm{ef}$ & $3.05 \pm 1.581$ \\
\hline Sebri & No pollination & $2.37 \pm 1.251$ & $0.0 \pm 0.0$ & $2.25 \pm 1.22 n$ \\
\hline Sebri & Open pollination & $5.68 \pm 1.77 \mathrm{e}$ & $2.81 \pm 1.27 \mathrm{ef}$ & $4.41 \pm 0.91 \mathrm{~g}$ \\
\hline Sebri & Coscia & $6.5 \pm 1.46 \mathrm{a}$ & $4.37 \pm 1.08 \mathrm{a}$ & $5.7 \pm 1.22 b$ \\
\hline Sebri & Natanzi & $4.62 \pm 1.2 \mathrm{~g}$ & $3.43 \pm 1.45 c$ & $4.29 \pm 1.51 \mathrm{~h}$ \\
\hline Sebri & Sardroud & $4.62 \pm 1.62 \mathrm{~g}$ & $3.12 \pm 1.31 \mathrm{~d}$ & $3.95 \pm 1.67 \mathrm{i}$ \\
\hline Sebri & Sebri & $1.25 \pm 1.06 \mathrm{o}$ & $1.5 \pm 1.03 \mathrm{jk}$ & $1.16 \pm 0.93 q$ \\
\hline Sebri & Shahmiveh & $3.87 \pm 1.08 \mathrm{i}$ & $3.43 \pm 1.09 \mathrm{c}$ & $3.52 \pm 0.98 \mathrm{j}$ \\
\hline Shahmiveh & Bartlett & $6.37 \pm 1.2 \mathrm{ab}$ & $4.18 \pm 0.75 a b$ & $5.83 \pm 1.18 \mathrm{a}$ \\
\hline Shahmiveh & No pollination & $1.93 \pm 1.34 \mathrm{n}$ & $0 \pm 01$ & $1.78 \pm 1.32 p$ \\
\hline Shahmiveh & Open pollination & $6.18 \pm 1.32 b c$ & $3.62 \pm 0.95 c$ & $4.56 \pm 0.85 f$ \\
\hline Shahmiveh & Coscia & $5.68 \pm 0.94 \mathrm{e}$ & $4.06 \pm 0.77 b$ & $5.24 \pm 1.02 \mathrm{~d}$ \\
\hline Shahmiveh & Natanzi & $4.56 \pm 1.09 \mathrm{gh}$ & $3.43 \pm 0.89 c$ & $3.96 \pm 1.03 \mathrm{i}$ \\
\hline Shahmiveh & Sardroud & $4.81 \pm 1.51 \mathrm{~g}$ & $2.18 \pm 0.91 \mathrm{~g}$ & $4.3 \pm 1.08 \mathrm{gh}$ \\
\hline Shahmiveh & Sebri & $4.31 \pm 1.01 \mathrm{~h}$ & $2.06 \pm 0.77 \mathrm{gh}$ & $3.93 \pm 1.38 \mathrm{i}$ \\
\hline Shahmiveh & Shahmiveh & $1.5 \pm 1.31 \mathrm{o}$ & $1.81 \pm 1.37 \mathrm{hi}$ & $1.15 \pm 1.01 \mathrm{q}$ \\
\hline
\end{tabular}

Means in each column followed by at least one the same letter are not significantly different at the 5\% of probability level-using LSD Test. 
Table 7. Mean of fruit number in interaction between the year of experiment and donor parent $\pm \mathrm{SD} ; \mathrm{n}=50$

\begin{tabular}{ccc|ccl}
\hline Year & Donor parent & Fruit number & Year & Donor parent & Fruit number \\
\hline 1 & Bartlett & $3.91 \pm 2.23 \mathrm{jk}$ & 3 & Bartlett & $4.33 \pm 1.77 \mathrm{ij}$ \\
1 & No pollination & $1.66 \pm 1.49 \mathrm{q}$ & 3 & No pollination & $2.08 \pm 1.31 \mathrm{p}$ \\
$\mathbf{1}$ & Open pollination & $\mathbf{6 . 4 1} \pm \mathbf{1 . 5 6 a}$ & $\mathbf{3}$ & Open pollination & $\mathbf{5 . 6 6} \pm \mathbf{1 . 4 3 b c}$ \\
1 & Coscia & $5.1 \pm 2.4 \mathrm{efg}$ & 3 & Coscia & $4.75 \pm 1.54 \mathrm{ef}$ \\
1 & Natanzi & $3.5 \pm 1.92 \mathrm{~lm}$ & 3 & Natanzi & $3.83 \pm 1.69 \mathrm{k}$ \\
1 & Sardroud & $4.3 \pm 2.01 \mathrm{i}$ & $\mathbf{3}$ & Sardroud & $\mathbf{5 . 5 8} \pm \mathbf{1 . 2 4 c d}$ \\
1 & Sebri & $2.25 \pm 1.76 \mathrm{p}$ & 3 & Sebri & $2.58 \pm 1.72 \mathrm{o}$ \\
1 & Shahmiveh & $3.33 \pm 2.1 \mathrm{~m}$ & 3 & Shahmiveh & $3.75 \pm 2.13 \mathrm{kl}$ \\
2 & Bartlett & $4.83 \pm 2.03 \mathrm{gh}$ & 4 & Bartlett & $4.41 \pm 1.78 \mathrm{gh}$ \\
2 & No pollination & $2.25 \pm 1.48 \mathrm{p}$ & 4 & No pollination & $3 \pm 0.85 \mathrm{n}$ \\
$\mathbf{2}$ & Open pollination & $\mathbf{5 . 9 1} \pm \mathbf{1 . 2 4 b}$ & 4 & Open pollination & $5 \pm 1.12 \mathrm{fgh}$ \\
2 & Coscia & $5.5 \pm 1.73 \mathrm{~cd}$ & $\mathbf{4}$ & Coscia & $\mathbf{5 . 3 3} \pm \mathbf{1 . 4 3 d e}$ \\
2 & Natanzi & $3.91 \pm 1.72 \mathrm{jk}$ & 4 & Natanzi & $3.66 \pm 1.77 \mathrm{kl}$ \\
$\mathbf{2}$ & Sardroud & $\mathbf{5 . 6 6} \pm \mathbf{1 . 2 3 b c}$ & 4 & Sardroud & $5.16 \pm 1.26 \mathrm{ef}$ \\
2 & Sebri & $2.83 \pm 1.89 \mathrm{no}$ & 4 & Sebri & $2.83 \pm 1.74 \mathrm{no}$ \\
2 & Shahmiveh & $4.16 \pm 2.62 \mathrm{ij}$ & 4 & Shahmiveh & $3.91 \pm 1.05 \mathrm{jk}$ \\
\hline
\end{tabular}

Means in each column followed by at least one the same letter are not significantly different at the $5 \%$ of probability level-using LSD Test.



Fig. 1. Effect of pollen donor on number of fruits with standard error $(\mathrm{SE}) \mathrm{n}=50$

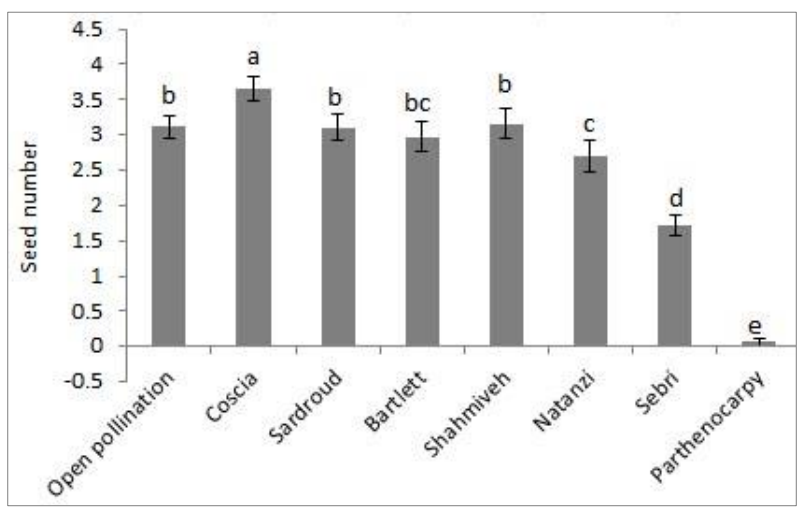

Fig. 2. Effect of pollen donor on number of seeds with standard error $(\mathrm{SE}) ; \mathrm{n}=50$

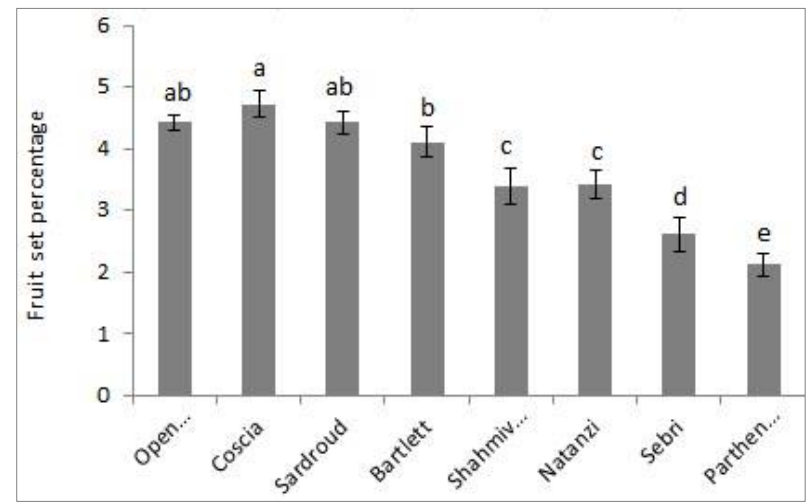

Fig. 3. Effect of pollen donor on fruit set percentage with standard error $(\mathrm{SE}) \mathrm{n}=50$

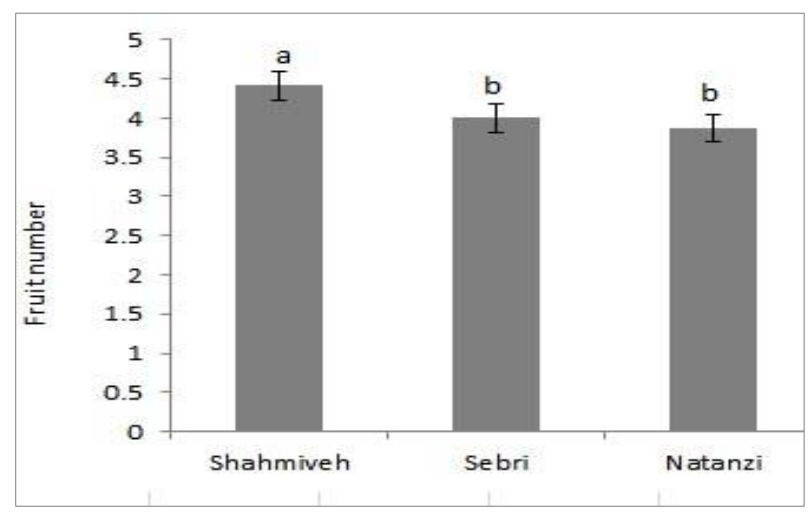

Fig. 4. Effect of recipient parents on number of fruit with standard error (SE); $n=50$ 
Regardless of the recipient parent, the highest fruit number was obtained in the result of open pollination with an average of 5.75 (Fig. 1). After that, 'Coscia' and 'Sardroud' as pollinators caused the highest value of this trait with an average of 5.18 and 5.06, respectively. The lowest number of fruits was obtained with 'Sebri' pollen and in parthenocarpic group. The highest seed number and fruit set percentage were obtained with 'Coscia' pollen (Figs. $2 \& 3$ ). Similarly, as for fruit number, the lowest result of the seed number and fruit set percentage was obtained for the non-pollinated flowers and with pollination with 'Sebri' pollen.

Regardless of the pollinizer, 'Shahmiveh' produced the highest fruit number (4.42) in comparison with 'Sebri' (4.0) and 'Natanzi' (3.87) (Fig. 4).

\section{DISCUSSION}

\section{Flowering time}

For a successful fruit production, the transfer of pollen grains on the stigma at the optimal time, the growth of the pollen tube and, ultimately, fertilization of the ovule are essential. The transfer of pollen grains is difficult without pollinators or in inappropriate weather conditions (Socias i Company et al. 2004); therefore, the compatible pollinizer with overlapping flowering time is necessary during effective pollination period (Mahmoudi et al. 2007). The flowering time of cultivars depends on the climatic conditions in place of orchard location. In some years, during which the temperature decreases in the late winter or early spring, flowering is delayed by several days. Abdollahi (2011) and Tahzibi Hagh (2010) proposed 'Sebri' as an early flowering and 'Shahmiveh' as well as 'Bartlett' as cultivars flowering a little bit later in Karaj climate conditions, which is consistent with our results.

At the time of orchard establishment, in addition to the pollen compatibility and the cultivation of two or more high yielding cultivars of high fruit quality, the overlapping the flowering time of the neighboring pollinators is also important (Wünsch \& Hormaza 2004). According to Ershadi et al. (2010), cultivars of at least $50 \%$ flowering overlapping with the main cultivar can be used as pollinators.
Accordingly to this, most of the studied cultivars here had a good overlapping in the flowering.

\section{Fruit set and seed numbers}

In all cross-pollination treatments, each pollinizer was able to fertilize recipient parents, but the degree of compatibility varied within combinations. The higher compatibility resulted in more fruit set percentage. Atefi (1990) reported that 'Coscia' was the best pollinizer for 'Shahmiveh' amongst others, including 'Sardroud', 'Dom-Kaj', 'William', 'Beurre Giffard', 'Beurre Hardy', 'Spadona' 'Duchess' and 'Coscia' in Karaj region. Mohammad Khani et al. (2002) recommended 'Coscia' and 'Bartlett' cultivars as suitable pollinizers for 'Shahmiveh'. Similar results were obtained in this study, but regarding 'Bartlett' that has the same time of flowering with 'Shahmiveh', highest fruit set percentage was obtained; therefore 'Bartlett' may be nominated as the most suitable cultivar for pollination of 'Shahmiveh'.

The 'Coscia' cultivar was previously recommended as an appropriate pollinizer for 'Dargazi' cultivar (Abdollahi 2011). In the current research, 'Coscia' was good pollinizer for 'Sebri' cultivar.

In this study, the highest values of the evaluated traits in 'Natanzi' was obtained with pollen of 'Shahmiveh', what confirms that local cultivars are good co-partners in pollination.

Pollen grain has a stimulating effect on the primary fruit set, but it seems that in hand self-pollination, incompatibility of pollen leads to a lower fruit set percentage in comparison with no pollination at all. In some cases, incompatibility occurs despite the fact that both sex organs are active. In these conditions, pollen tubes are not able to reach the ovary and fertilize the ovules and, consequently, fruit set is limited (Hiratsuka \& Zhang 2002). These results contradict with the results of Zeratgar et al. (2012), who showed the important role of pollen stimulation contrary to the self-pollination. In evaluating the fruit set percentage and fruit number, it was also determined that 'Sebri' and 'Natanzi' had a greater tendency towards parthenocarpy than 'Shahmiveh'.

The percentage of optimal fruit set in each cultivar was obtained with a specific pollinizer. Nowadays, with introducing a new cultivar, self-(in)com- 
patibility and cross-(in) compatibility of it are immediately investigated (Ortega \& Dicenta 2004). Owing to the cross-incompatibility between different cultivars, sometimes the cultivation of only two different cultivars together will not solve the problem of self-incompatibility (Arzani \& Goharkhay 2005).

According to Babaei et al. (2013), pear cultivars native to East Asia are characterized by limited number of the genetic components. Therefore, the use of genetically distant pollinizers that ensures less of self-incompatible alleles can increase the fruit set percentage (Zisovich et al. 2010). It seems that this is the reason why 'Coscia' and 'Bartlett' are good pollinizers for 'Sebri' and 'Shahmiveh'.

As mentioned, open pollination in the first year resulted in the highest average of fruit number. In the next years, the fruit number in open pollination treatment decreased and its superiority was reduced. Perhaps such a process can be explained by the high yield that forces alternative fruiting in some cultivars, as in 'Sebri'.

A low fruit number in the non-pollinated treatment varied in different years. This suggests the influence of climatic conditions on the process of parthenocarpy.

Weather conditions during years of experiment did not influence significantly results of the fruit set. The honeybees have a maximum activity at the temperatures $10-18^{\circ} \mathrm{C}$ (Khadivi 2012), and the average daily temperature in April was sufficient for bee activity. In different years, several factors, including the quantity and quality of water, soil quality, pruning, fertilization and environmental conditions before and after flowering affect the fruit set percentage (Ortega \& Dicenta 2004).

\section{CONCLUSION}

Regarding the self- and cross-incompatibility in different cultivars of pear, it is recommended that two to three pear cultivars were cultured in an orchard that have pollen compatibility and bloom at least partly in the same time. The compatible pollinizers should be selected from commercial cultivars with high yield and quality of fruit and good marketability. According to the results of this research, 'Coscia', 'Sebri', 'Bartlett', 'Shahmiveh' and 'Natanzi' can be cultivated together in the orchard, because 'Shahmiveh', 'Sebri' and 'Natanzi' were effectively fertilized with 'Bartlett', 'Coscia' and 'Shahmiveh'.

\section{REFERENCES}

Atefi J. 1990. Determination of the best pollinizer for eight commercial pear cultivars. $4^{\text {th }}$ Congress of Iranian Horticultural Science, Kerman, Iran. [in Persian with English abstract]

Abdollahi H. 2011. Pear, botany, cultivars and rootstocks. Ministry of Jihad-e-Agriculture, Tehran, Iran, 200 p. [in Persian with English abstract]

Arzani K., Goharkhay S. 2005. Self-compatibility and cross-compatibility studies on commercial sweet cherry (Prunus avium L.) cultivars in Iran. $5^{\text {th }}$ International Cherry Symposium, June 6-10, Bursa, Turkey.

Babaei F., Khorramdel Azad M., Abdollahi H., Torabi S., Aminafshar M. 2013. Detection of pear S-alleles by setting up a revised identification system. Acta Horticulturae 976: 339-343. DOI: 10.17660/actahortic.2013.976.46.

Dorostkar M., Mostafavi M., Sanei Sharia Tpanahi M., Hasani D., Khalighi A., Nikzad A. 2011. Self-compatibility and suitable planting combination of commercial cultivars of almond. Seed and Plant Improvement Journal 271(4): 449-457. [in Persian with English abstract]

Ershadi A., Kalhori M., Imani A., Valizadeh B., Dashti F. 2010. Determination of suitable pollinizers for almond (Prunus dulcis) cultivars and genotypes "Shahrood 12", "Shokoufeh" and "K-4-10" using specific amplification of S-alleles. Agricultural Biotechnology (Agricultural Research) 9(2): 7-15. [in Persian with English abstract]

Gharghani A., Talaei A.R., Zamani Z., Fattahi Moghadam M.R., Hajnajari H., Gardiner S. 2009. Necessity of covering in controlled pollination of apple by detection of microsatellite alleles in offspring of 'Golden Smoothee' 'Shafi Abadi'. Water and Soil Science (Journal of Science and Technology of Agriculture and Natural Resources) 13(48): 1-15 [in Persian with English abstract]

Hiratsuka S., Zhang S.L. 2002. Cultivar differences in the expression of self-incompatibility in Japanese pears. Acta Horticulturae 587: 437-448. DOI: 10.17660/actahortic.2002.587.58. 
Hormaza J.I., Herrero M. 1996. Dynamics of pollen tube growth under different competition regimes. Sexual Plant Reproduction 9: 153-160. DOI: 10.1007/BF02221395.

Jalili Marandi R. 2002. Pomology. Publication of Jahad Daneshgahi, Oromiye, Iran, $289 \mathrm{p}$.

Khadivi A. 2012. Pomology (temperate, tropical, subtropical and small fruits). Publication of Agricultural Education and Extension, Tehran, Iran, 468 p. [in Persian with English abstract]

Mahmoudi M., Arzani K., Bouzari N. 2007. Pollination, pollen tube growth and determination of suitable pollinizer for sweet cherry (Prunus avium L.) cultivar Ghermez Rezaeieh. Seed and Plant Improvement Journal 23: 571-585. [in Persian with English abstract]

Mohammad Khani A., Lessani H., Talaei A.R., Babalar M. 2002. Study of flower phenology, self-compatibility and determination of the best pollinizer for 'Shahmiveh' pear. Iranian Journal of Horticultural Science and Technology 3: 67-76. [in Persian with English abstract]

Mousavi A., Babadaei R., Fatahi R., Zamani Z., Dicenta F., Ortega E. 2014. Self-incompatibility in the Iranian almond cultivar 'Mamaei' using pollen tube growth, fruit set and PCR technique. Journal of Nuts (International Journal of Nuts and Related Sciences) 5: 1-10. [in Persian with English abstract]

Ortega E., Dicenta F. 2004. Suitability of four different methods to identify self-compatible seedlings in an almond breeding programme. Journal of Horticultural Science and Biotechnology 79: 747-753. DOI: 10.1080/14620316.2004.11511837.

Ramírez F., Davenport T.L. 2013. Apple pollination: A review. Scientia Horticulturae 162: 188-203. DOI: 10.1016/j.scienta.2013.08.007.

Sadat Mousavi S. 2009. Identification of self (cross)-incompatibility and chilling requirement in some Asian pear (Pyrus serotina Rehd.) genotypes.
M.Sc. Thesis, Tarbiat Modares University, Tehran, Iran, 115 p. [in Persian with English abstract]

Sanzol J., Herroro M. 2002. Identification of self-incompatibility alleles in pear cultivars (Pyrus communis L.). Euphytica 128: 325-331. DOI: 10.1023/A:1021213905461.

Sharifani M. 2002. Influence of pollen sources and seed number on characteristics of pear fruit. Journal of Agricultural Sciences and Natural Resources 8(3): 45-53. [in Persian with English abstract]

Socias i Company R., Alonso J.M., Gómez Aparisi J. 2004. Fruit set as an evaluation criterion in almond breeding. Acta Horticulturae 663: 763-768. DOI: 10.17660/ActaHortic.2004.663.138.

Tahzibi Hagh F. 2010. Complementary evaluation of some vegetative and reproductive characteristics in some Iranian pear cultivars at national pear collection. M.Sc. Thesis, Islamic Azad University of Abhar, Abhar, Iran. 300 p. [in Persian with English abstract]

Wünsch A., Hormaza J.I. 2004. S-allele identification by PCR analysis in sweet cherry cultivars. Plant Breeding 123: 327-331. DOI: 10.1111/j.14390523.2004.00984.x.

Zeratgar H., Davarinejad G.H., Abdollahi H. 2012. Determination of suitable pollinizer for some Iranian native pear cultivars. Seed And Plant Production Journal 28: 435-448. [in Persian with English abstract]

Zisovich A.H., Raz A., Stern R.A., Goldway M. 2010. Syrian pear (Pyrus syriaca) as a pollinator for European pear (Pyrus communis) cultivars. Scientia Horticulturae 125: 256-262. DOI: 10.1016/j.scienta.2010.03.013.

Zisovich A.H., Stern R.A., Shafir S., Goldway M. 2004. Identification of seven $S$-alleles from the European pear (Pyrus communis) and the determination of compatibility among cultivars. Journal of Horticultural Science and Biotechnology 79: 101-106. DOI: 10.1080/14620316.2004.11511720. 